\title{
SURFACE ANALYSIS OF TITANIUM ELECTRODES
}

\author{
J. González-García, G. Sánchez-Cano, A. Aldaz and V. Montiel. \\ Departamento de Química Física. Universidad de Alicante. \\ Apartado 99. 03080 Alicante (Spain)
}

\section{J.L.G. Fierro.}

Instituto de Catálisis y Petroleoquímica. CSIC. Campus UAM. 28049 Madrid (Spain)

\begin{abstract}
Electrochemical, SEM, FTIR and XPS studies of adsorbed species formed during the treatment of titanium surfaces with oxalic-oxalate solutions have been carried out. FTIR and XPS experiments show that the use of this treatment prevents the growth of a thick oxide layer on the titanium surface.
\end{abstract}




\section{INTRODUCTION}

Nowadays, there is much cause for worry about pollution caused by industrial effluents containing heavy metals. Different electrochemical methods have been proposed for the elimination of these metals [1] normally as bulk metals, oxygen evolution being very often the anodic reaction.

Different types of anodic materials are currently used as anodes for this reaction. These materials present different degrees of corrosion and/or passivation during use[2]. Among them, DSA (Dimensionally Stable Anodes) are the most commonly used in pilot-laboratory plants and on an industrial scale as $\mathrm{Cl}_{2} / \mathrm{DSA}$ and $\mathrm{O}_{2} / \mathrm{DSA}$ electrodes. $\mathrm{Cl}_{2}$ /DSA anodes have given very satisfactory results in chlorine-sodium hydroxide cells $[3,4]$, but the results obtained using $\mathrm{O}_{2} / \mathrm{DSA}$ in different electrochemical applications are not so good [5]. Another type of anode used in commercial processes are lead dioxide anodes that normally have a thin film of a precious metal $(\mathrm{Pt}, \mathrm{Au}, \ldots)$ between $\mathrm{Ti}$ and $\mathrm{PbO}_{2}$ in order to avoid formation of titanium oxides that produces a very high IR drop [6]. In spite of the fact that all the electrodes are dimensionally stable localized corrosion may occur caused, for example, by bad current distribution. This non uniform corrosion can produce the dissolution of oxides of the precious metal that have the following consequences:

1. The rise in the price of the process caused by anodes replacement.

2. The possible migration of the cations of the precious metal oxides to the cathode with the subsequent catalysis of the hydrogen evolution reaction, a competitive reaction for metal deposition.

That is why the preparation of lead dioxide anodes supported onto titanium substrate without a precious metal interphase still makes sense for certain purposes. Since the electrochemical oxidation of organic compounds is a very good method of 
decreasing the COD (Chemical oxygen demand) of effluents, these anodes can be very useful due to their very high oxygen overvoltage. Many attempts to prepare this type of anode have been carried out [7] and all of them have shown that the pretreatment of the surface of the titanium substrate before lead dioxide anodic electrodeposition is crucial in order to obtain a long-lived anode for industrial purposes.

Wabner et col. [8] suggested a method of surface treatment for titanium in which an interphase of precious metal is not employed and in which lead dioxide electrodes were obtained with a duration of over 100 hours at a current density of $100 \mathrm{~mA} \mathrm{~cm}^{-2}$.

This work presents a treatment of the titanium substrate that avoids precious metal plating giving very good adherence to the lead dioxide layer. This method is compared to others already described in the bibliography and analyzed using techniques such as EDX, SEM, FTIR, XPS and voltammetry.

\section{EXPERIMENTAL}

The voltammetric set-up consisted of an Amel 553 potentiostat, an H-Q Instruments model 305 programmable function generator and a Philips X-Y PM 8133 recorder. The polarization curves were recorded in $1 \mathrm{M}$ solutions of sulphuric acid or nitric acid (Merck a. r.). The titanium metal is from Goodfellow (99.6\%). The solutions were prepared with ultrapure water (Millipore Milli-Q) and were deoxygenated by nitrogen (SEO N48) bubbling. All measurements were carried out at room temperature and at a sweep rate of $50 \mathrm{mV} \mathrm{s}^{-1}$. A saturated calomel electrode (SCE) was used as reference electrode. 
The Scanning Electron Microscope (SEM) employed to obtain topographical views of the surface was a JSM-840 JEOL microscope. The SEM also provided information about the different elements present on the surface using the energy dispersive X-ray detector (Link QX 200 EDX).

The Fourier transform IR (FTIR) spectrometer was a 510P Nicolet of diffuse reflectance. The spectra were obtained employing 10 scans with a resolution of $2 \mathrm{~cm}^{-1}$.

X-ray photoelectron (XPS) spectra were obtained with a Fisons ESCALAB MkII 200R spectrometer provided with a hemispherical electron analyzer and a Mg anode Xray exciting source $(\mathrm{MgK} \alpha=1253.6 \mathrm{eV})$. The samples were pressed into small aluminium cylinders and then mounted on a rod placed in the pretreatment chamber of the spectrometer. The samples were pumped to ca. $10^{-6}$ Torr before they were moved into the analysis chamber. The residual pressure in this ion-pumped analysis chamber was maintained below $3 \times 10^{-9}$ Torr during data acquisition. $20 \mathrm{eV}$ energy regions of the photoelectrons of interest at a pass energy of $20 \mathrm{eV}$ were chosen for each sample. Each spectral region was signal averaged for a number of scans to obtain good signal to noise ratios. A binding energy (BE) of $284.9 \mathrm{eV}$, corresponding to the $\mathrm{C} 1 \mathrm{~s}$ peak, was used as an internal standard. The spectra were collected in a PDP computer and then the peak areas were measured assuming a curved background.

Two different superficial treatments have been studied. Method (I) consists on a conventional treatment of activation of titanium through a chemical attack with $1 \mathrm{M}$ $\mathrm{NH}_{4} \mathrm{HF}_{2}$. Treatment (II), proposed in this paper and partly based on Wabner's work, consists on two stages. Thus, an initial physical attack of the surface by sand blasting is followed by a chemical treatment consisting of two steps. First, the surface is submitted to a 60 minute treatment in $15 \%$ oxalic acid. After that, it is immersed in $1.25 \mathrm{M}$ oxalic acid and $0.2 \mathrm{M} \mathrm{Ti}(\mathrm{IV})$ oxalate solution for 0.5 hours. All these treatments are carried out at boiling temperature. 


\section{RESULTS AND DISCUSSION}

\section{SEM and EDX characterization.}

The morphological details of the substrate surface for the different treatments are compared in a series of SEM photomicrographs (Fig. 1). Figure 1a and 1b show the non treated titanium and titanium surfaces treated with $1 \mathrm{M} \mathrm{NH} \mathrm{NH}_{2}$ (method I). It can be observed that chemical corrosion is localized on the surface defects providing a texture with a much more defined grain. The influence of sandblasting before applying the chemical treatment can be seen by comparison of figures $1 \mathrm{c}$ and $1 \mathrm{~d}$. Figure $1 \mathrm{c}$ and $1 \mathrm{~d}$ show a scanning electron micrograph of a surface prepared according to our method with or without sandblasting. The sandblasting produces a more microrough surface with many small deep pores which will favour the adherence of lead dioxide deposit.

\section{Electrochemical characterization.}

In order to get more information about the characteristics of the titanium surface, the voltammetric behaviour of these surfaces obtained by using the different surface treatments have been studied. Figure 2 shows the voltammetric profile of a surface treated according with method (I) in $1 \mathrm{M} \mathrm{H}_{2} \mathrm{SO}_{4}$. The potentiodynamic sweep started at $E_{i}=-0.59 \mathrm{~V}$ vs SCE which corresponds to a potential a little more negative than the critical one. The curves shown correspond to different waiting times at the initial potential $\mathrm{E}_{\mathrm{i}}$ before the polarization programme was started. For all of them, the profile presents an oxide growth plateau at higher potential than $0 \mathrm{~V}$. However, the voltammetric curve in the potential range of the active-passive transition (between -0.6 to $0.4 \mathrm{~V}$ approximately) is different depending on the waiting time. For $\mathrm{t}=0$, the voltammetric profile shows two shoulders: one of them well-defined, located at approximately $0 \mathrm{~V}$ (peak a), and another one located at less positive potential than -0.5 $\mathrm{V}$ (peak b). As the waiting time increases, peak a disappears and peak $\mathbf{b}$ is better 
defined. It has been observed that with the increase of the waiting time the voltammetric response becomes repetitive as shown in fig. 3. The typical behaviour of valve metals was verified and the characteristic titanium curve [9] is obtained with the increase of the waiting time. It is interesting to analyze the voltammetric study carried out for the titanium surface treated with $\mathrm{NH}_{4} \mathrm{HF}_{2}$. It is admitted in the bibliography [10] that the treatment with $\mathrm{NH}_{4} \mathrm{~F}$ in the presence of $\mathrm{HF}$ and other acids can lead to a situation of "passivation" due to the formation of a surface hydride. Even the curve obtained for $\mathrm{t}=0$ minutes presents the characteristic $\mathrm{j}$-E response of metals with a thin protecting film [11]. Otsuka et col. suggests that the peak at potentials between -0.1 and $0 \mathrm{~V}$ is due to the hydride oxidation [12]. Recent works, using SIMS have shown the existence of these hydrides [13].

The voltammetric response of titanium treated when using treatment (II), fig 4, is very different from that obtained using treatment (I). The oxidation current is smaller in the interval potential 0 to $2 \mathrm{~V}$. A sharp increase in the current is obtained for potentials more positive than $2.5 \mathrm{~V}$.

Taking into account that the process of electrodeposition of lead dioxide is carried out in nitric acid medium, figure 5 shows the superposition of voltammograms obtained in this electrolyte for a titanium surface treated by methods (I) and (II). Anodic currents are smaller for treatment (II), as in the previous case.

It is important to point out that the current densities shown in the voltammograms are referred to the geometric area of the electrode. Treatment (II) produces a higher surface area than treatment (I) which implies that the real current densities of the voltammograms corresponding to method (II) must be smaller than ones for method (I). At this moment it is not possible to get a detailed interpretation of the voltammograms because the contribution of double layer charging current is very high for these electrodes of high surface areas. 


\section{FTIR characterization.}

Diffuse reflectance FTIR has been used in order to characterize the superficial state of titanium after the treatment (II) and to try to obtain an explanation for its voltammetric behaviour.

Several samples of titanium have been prepared according with the following procedure: After being roughened with sandblansting, they were boiled during 1 hour in a $15 \%$ oxalic acid solution (first part method (II)). After this the samples were boiled for different periods of time in a $1.25 \mathrm{M}$ oxalic acid plus $0.2 \mathrm{M} \mathrm{Ti}(\mathrm{IV})$ oxalate solution. These times were 0, 0.5, 2 and 3 hours (Figs. 6a, 6b, 6c and 6d).

A signal at $1680 \mathrm{~cm}^{-1}$ appears with the increases of the time. This signal can be assigned to the antisymmetric vibration of the $\mathrm{C}=\mathrm{O}$ groups of a $\mathrm{Ti}(\mathrm{IV})$-oxalate species adsorbed on the titanium surface. This adsorption is low as shown the variation of the intensity of the signal with the adsorption time.

\section{XPS characterization.}

A more precise characterization of the surface of the electrode submitted to method (II) was set out by means of photoelectron spectroscopy. The C1s, O1s, Ti2p core level spectra, and eventually the $\mathrm{N} 1 \mathrm{~s}, \mathrm{~Pb} 4 \mathrm{f}$ and $\mathrm{Na} 1 \mathrm{~s}$ spectra due to impurities, were recorded for all samples. The binding energy (BE) values of core electrons in the surface oxygen atoms of the electrode are summarized in Table 1. It is important to note that all samples show significant carbon contamination. Within the binding energy region corresponding to $\mathrm{C} 1 \mathrm{~s}$ photoelectrons three well defined carbon species can be discerned: a peak placed at low binding energy due to $\mathrm{C}-\mathrm{C}$ and $\mathrm{C}-\mathrm{H}$ species from contamination, usually considered as an internal standard for calibration of BE scale, a second peak at intermediate $\mathrm{BE}$ assigned to $\mathrm{C}-\mathrm{O}$ species, and a third one placed at $\mathrm{BE}$ 
close to $289 \mathrm{eV}$ whose origin lies in $\mathrm{C}=\mathrm{O}$ species [14]. The most intense peak of titanium $\left(\mathrm{Ti} 2 \mathrm{p}_{3 / 2}\right)$ was found in all cases in the energy region $458.4-458.7 \mathrm{eV}$ which closely corresponds with the expected value for fully oxidized $\mathrm{Ti}^{4+}$ species [15]. This finding is consistent with the relative ease with which $3 \mathrm{~d}$ transition metals became oxidized by air moisture. $\mathrm{TiO}_{\mathrm{x}}$ species ( $\mathrm{x}$ close to 1 ) and $\mathrm{Ti}^{\circ}$ could be detected in presence of a major quantity of fully oxidized $\mathrm{TiO}_{2}$ species after bombardment with an $\mathrm{Ar}^{+}$beam accelerated at $2.5 \mathrm{keV}$ and working with a current density of ca. $300 \mathrm{nA} \mathrm{cm}^{-2}$ for a period of 10 minutes. On the basis of this result, the thickness of the surface oxide layer was estimated to be 8-10 atomic layers. Simultaneously, the $\mathrm{C} 1$ s peak changed dramatically after sputtering. As neither $\mathrm{C}-\mathrm{O}$ nor $\mathrm{C}=\mathrm{O}$ species were observed on sputtered samples, and considering the relative ease with which Ti surface is oxidized by moisture, the preferential removal of $\mathrm{C}-\mathrm{O}$ and $\mathrm{C}=\mathrm{O}$ species points out that method (II) produces a very thin $\mathrm{TiO}_{2}$ layer on which oxalate adsorption occurs.

XPS has also been used to obtain information about the electrochemical behaviour of the titanium samples treated using method (II). These samples were polarized at different potentials $-0.59,2.34$ and $>6 \mathrm{~V}$ vs $\mathrm{SCE}$ (b, c and d points in Fig. 7). Thus Figure 8 displays the O1s peak of a Ti electrode polarized at the different potentials (spectra $8 \mathrm{~b}, 8 \mathrm{c}$ and $8 \mathrm{~d}$ ) compared to a non-polarized sample (spectrum 8a) with identical pretreatment. The component of the peak at lower $\mathrm{BE}$ is typical of $\mathrm{O}^{2-}$ species, however that placed at higher BEs is attributed to less electron -rich oxygen species such as $\mathrm{OH}^{-}$or $-\mathrm{C}=\mathrm{O}[16]$. The relative abundance of these two major $\mathrm{O}-$ species was found to depend markedly on the polarization potential. In some cases a very small O1s peak placed at the highest BE has also been observed. The origin of this peak lies in the adsorption of molecular water.

Spectrum 8a shows $\mathrm{O}^{2-}$ species at low $\mathrm{BE}$, the oxygen corresponding to "oxalicoxalate" species and adsorbed molecular water at higher BE. When polarizing at $-0.59 \mathrm{~V}$ vs SCE (spectrum 8b), the disappearance of adsorbed molecular water, and the 
displacement of the intermediate oxygen signal to typical $\mathrm{BE}$ values of $\mathrm{C}=\mathrm{O}$ species, are observed. The existence of a cathodic current during polarization is in agreement with this result. If we polarize at $2.34 \mathrm{~V}$ vs SCE, (spectrum $8 \mathrm{c}$ ), the displacement of the intermediate signal to typical values of $\mathrm{C}=\mathrm{O}$ species is also seen, but the adsorbed molecular water does not disappear. However, if the electrode is polarized to very positive potentials, higher than 6V SCE (spectrum 8d), a slightly different behaviour appears; the intermediate oxygen signal is shifted to lower $\mathrm{BE}$ values, due to $\mathrm{OH}^{-}$ groups. These facts are in agreement with the increase of the positive current, Fig 7, the existence of this anodic current can be explained as due to the oxidation of adsorbed organic compounds, water oxidation (adsorption of $\mathrm{OH}$ ) and titanium oxidation.

The comparison of O1s spectra for samples treated with method (II), with the spectra obtained for samples treated according to Wabner's method, Fig 9, reveals that this last procedure produces a smaller proportion of oxygen species placed at higher BEs. Moreover, a careful analysis of the components of O1s spectrum in the samples indicates substantial changes in the position of the peak placed at higher BE. The somewhat lower value of BE for the samples obtained by a treatment of $0.5 \mathrm{~h}$ in oxalicoxalate in comparison with that obtained by a treatment of $2 \mathrm{~h}$. (Wabner's method) shows that for short periods of time, the surface of the electrode is mainly populated by $\mathrm{OH}$ species but these species become replaced by oxalate species if the treatment is extended for longer periods of time.

\section{CONCLUSIONS}

The use of several techniques of different characteristics and sensitivity allowed us to give a qualitative description of the titanium surface obtained using treatment (II). 
EDX and SEM studies show that by using the proposal method (II) a uniform roughness is obtained on the surface with small deep holes but without sand contamination.

The voltammetric study shows that a passive layer of massive $\mathrm{TiO}_{2}$ is not produced for potentials lower than $2.34 \mathrm{~V}$.

The FTIR study and XPS analysis reveal the existence of a film of $\mathrm{TiO}_{2}$ smaller than 10 atomic layers on which is absorbed a " $\mathrm{C}=\mathrm{O}$ species" probably oxalic-oxalate. This structure constitutes a thin film which protects the titanium surface from the formation of a thick oxide film in the potential range of 0 to $2 \mathrm{~V}$ (SSE).

So, the obtention of a homogeneously rough surface with small deep holes using treatment (II) and the inexistence of a thick oxide layer of the Ti surface gives high hopes of obtaining an adherent long life $\mathrm{PbO}_{2}$ deposit onto titanium which behaviour could be comparable to that obtained using a Ti/Pt/ $\mathrm{PbO}_{2}$.

\section{ACKNOWLEDGEMENTS}

One of the authors (J.G.-G.) is grateful to the "Consellería de Cultura, Educación y Ciencia, de la Generalidad Valenciana" for his research grant. Thank are also given to "Fundación Cultural Caja de Ahorros del Mediterráneo" for its economical support. The authors wish to thank Dr. Diego Cazorla for valuable advice on FTIR experiments. 


\section{REFERENCES}

1. $\quad$ R. J. Marshall and F. C. Walsh, Surf. Technol., 24 (1985) 45.

2. F. Beck, Electrochim. Acta, 34 (1989) 811.

3. S. Trasatti and W.E. O'Grady, in "Advances in Electrochemistry and Electroanalytical Engineering". H. Gerischer and C.W. Tobias Eds., WileyInterscience, New York, (1981) Vol. 12, p. 177.

4. A. Nidola, in "Electrodes of Conductives Metal Oxides". Edited by S. Trasatti, Elsevier, Amsterdam (1981) p. 627.

5. G.P. Vercesi, J. Rolewicz, CH. Comninellis and J. Hinden, Thermochim. Acta, $176(1991) 31$.

6. G.H. Kelsall, ECRC/N 1060.

7. CH. Comninellis, E. Plattner, J. Appl. Electrochem.,12 (1982) 399.

8. H.P. Fritz, D. Wabner, R. Huss (R.W.E. A.G.) Ger. Offen. 2444691 (1 April 1976).

9. R.M. Torresi, O.R. Cámara, C.P. de Pauli, M.C. Giordano, Electrochim. Acta, 32 (1987) 1291.

10. W. J. James and M. E. Straumanis, in "Encyclopedia of Electrochemistry of the Elements" Allen J. Bard Ed., Marcel Dekker, New York, (1976) Vol 5, Ch. 7, p. 353.

11. Viasta Brusic', in "Oxides and Oxides Films". John W. Diggle Ed., Marcel Dekker, New York,(1972) Vol 1, Ch. 1, p. 5.

12. R. Otsuka, Z. Metallk., 47 (1956) 714.

13. D. J. Blackwood, L. M. Peter, H. E. Bishop, P. R. Chalker and D. E. Williams, Electrochim. Acta, 34 (1989) 1401.

14. "Practical Surface Analysis by Auger and X-Ray Photoelectron Spectroscopy".

D. Briggs and M.P. Sean. Eds., Wiley, New York, 1983.

15. M. Murata, K. Wakino and S. Ikeda, J. Electron Spectros., 10 (1975) 459.

16. L.G. Tejuca, A. T. Bell, J.L.G.Fierro and M.A. Peña, Appl Surf. Sci., 31 (1988) 301. 


\section{LEGEND OF THE FIGURES}
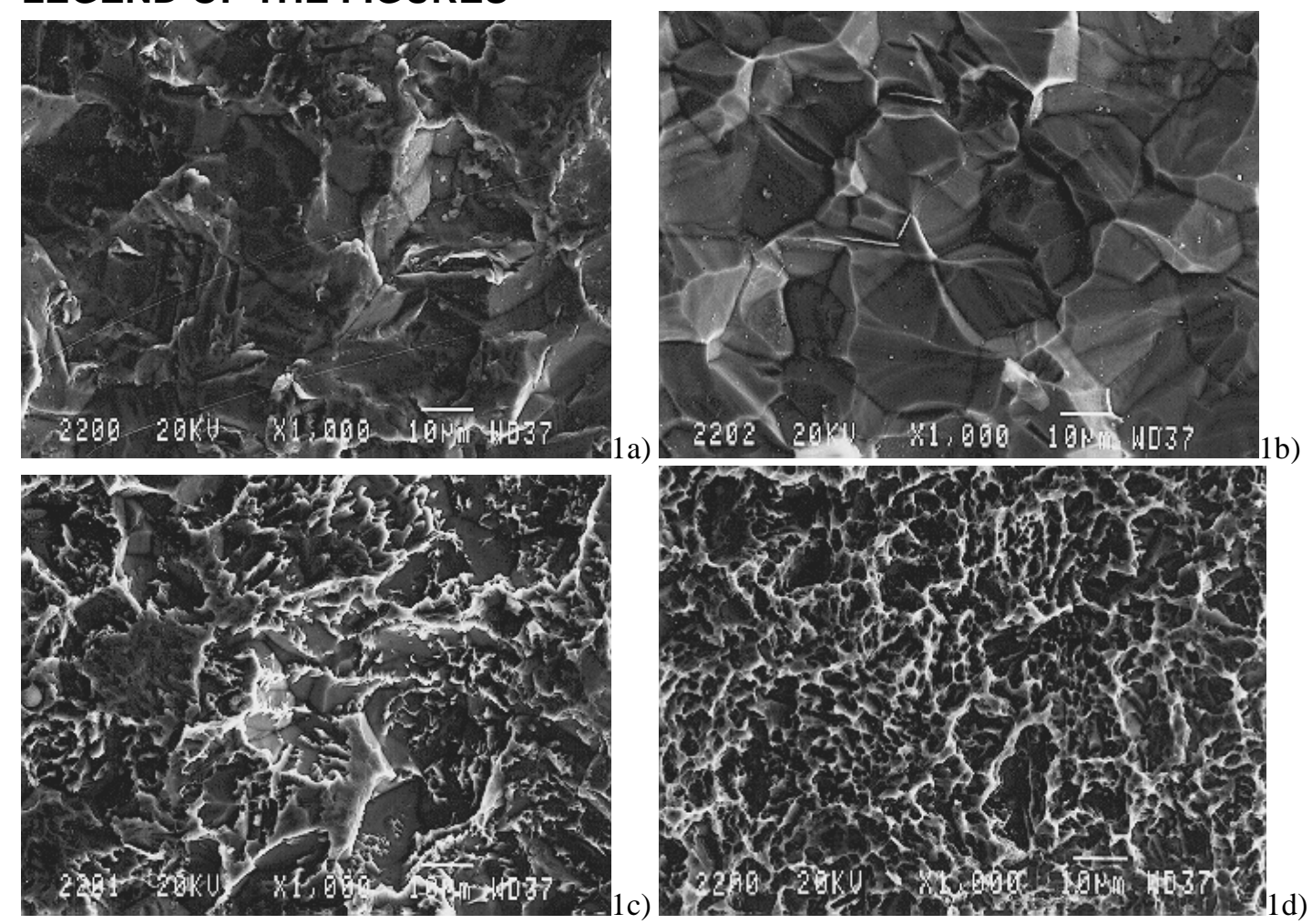

Figure 1: Photomicrographs of titanium surface. (1a) Nontreated titanium. (1b) Titanium treated with $1 \mathrm{M} \mathrm{NH}_{4} \mathrm{HF}_{2}$ (method I). (1c) Titanium treated with method (II) without sandblasting. (1d) Titanium fully treated with method (II).

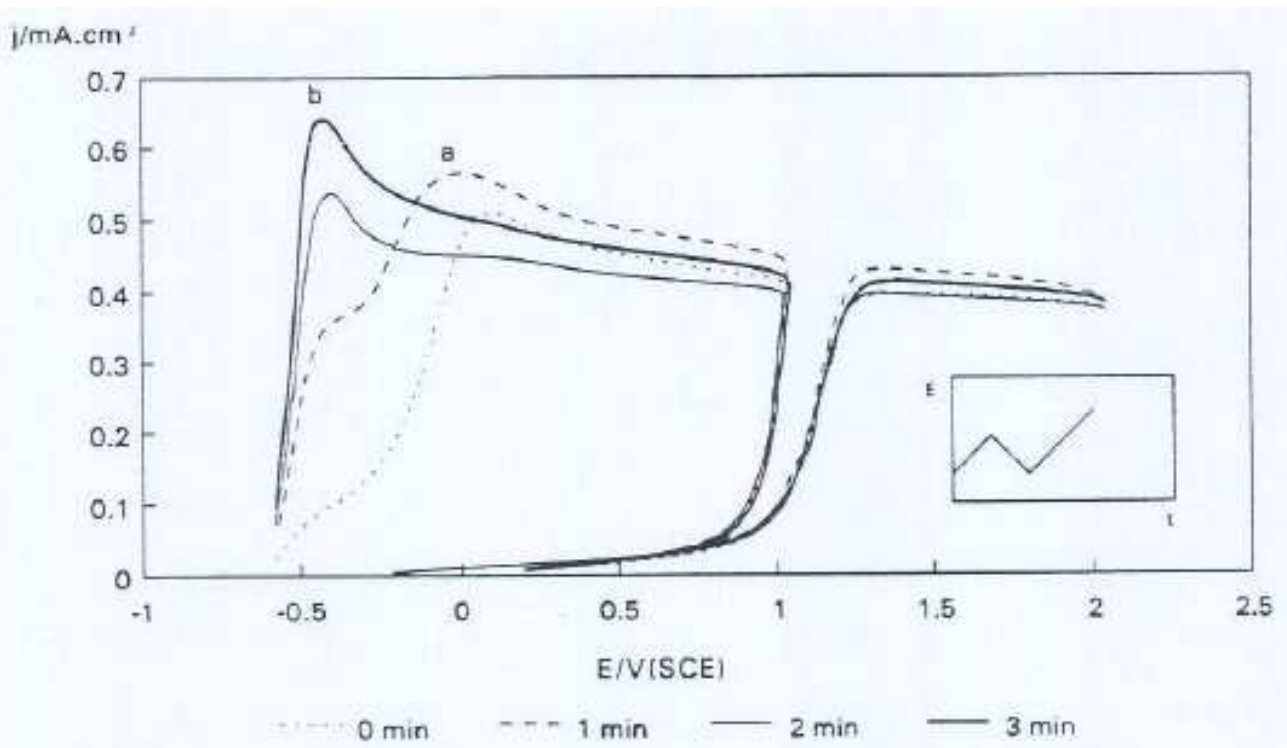

Figure 2: Voltammetric $\mathrm{j}-\mathrm{E}$ profile for a titanium electrode treated by method (I). $\mathrm{E}_{\mathrm{i}}=$ $-0.59 \mathrm{~V}$ waiting time $\mathrm{t}=0,1,2$ and 3 minutes before starting the polarization programme (see window), $\mathrm{v}=50 \mathrm{mV} \mathrm{s}^{-1}$, room temperature, electrolyte $1 \mathrm{M} \mathrm{H}_{2} \mathrm{SO}_{4}$. 


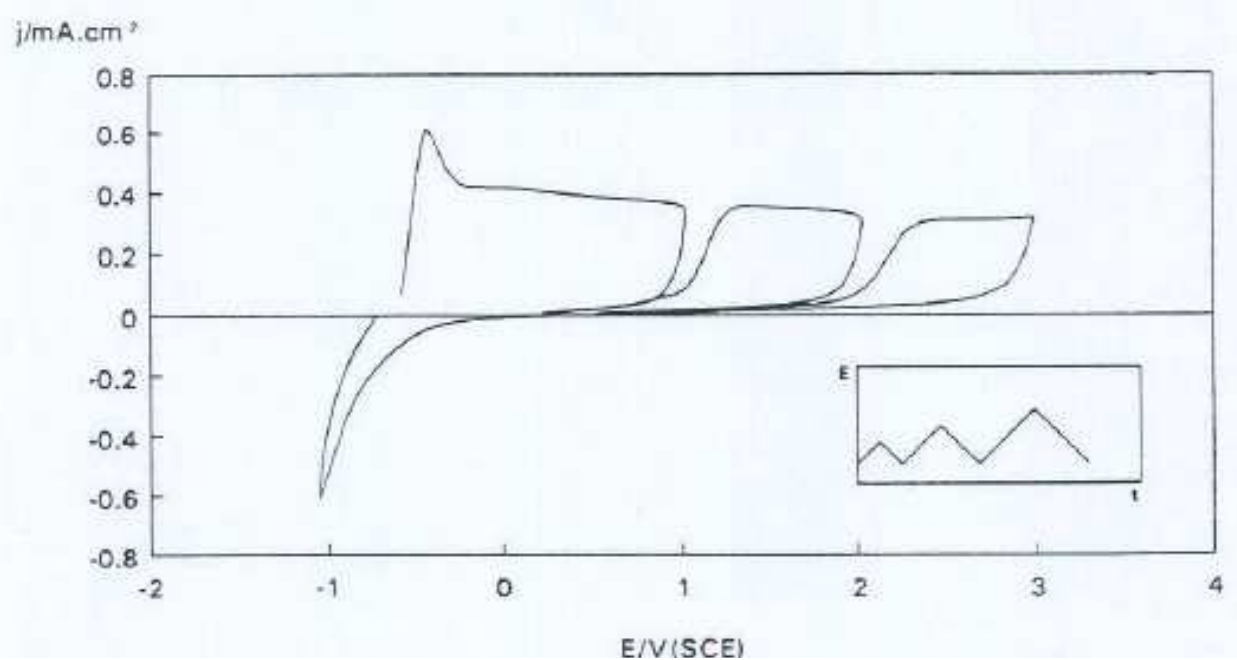

Figure 3: Voltammetric $\mathrm{j}-\mathrm{E}$ profile for a titanium electrode treated by method $(\mathrm{I}) . \mathrm{E}_{\mathrm{i}}=$ $-0.59 \mathrm{~V}$ waiting time $\mathrm{t}=10$ minutes before starting the polarization programme (see window), $\mathrm{v}=50 \mathrm{mV} \mathrm{s}^{-1}$, room temperature, electrolyte $1 \mathrm{M} \mathrm{H}_{2} \mathrm{SO}_{4}$.

jimA.cm

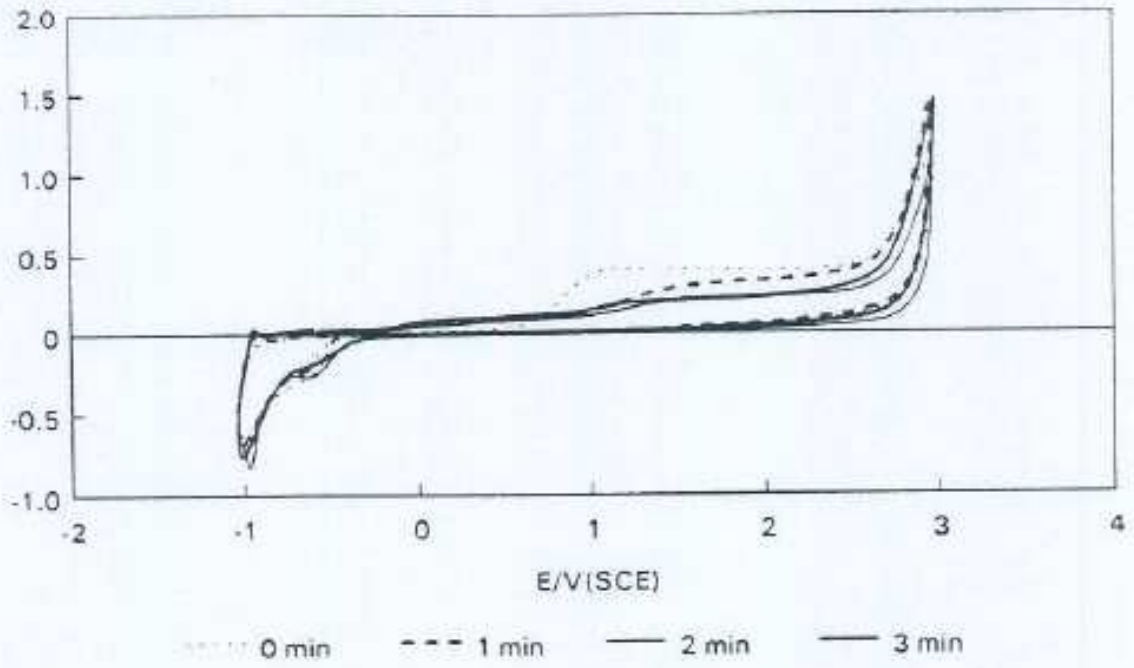

Figure 4: Voltammetric $\mathrm{j}-\mathrm{E}$ profile for a titanium electrode treated by method (II). $\mathrm{E}_{\mathrm{i}}=$ $-0.59 \mathrm{~V}$ waiting time $\mathrm{t}=0,1,2$ and 3 minutes before starting the sweep, $\mathrm{v}=50 \mathrm{mV} \mathrm{s}^{-1}$, room temperature, electrolyte $1 \mathrm{M} \mathrm{H}_{2} \mathrm{SO}_{4}$. 


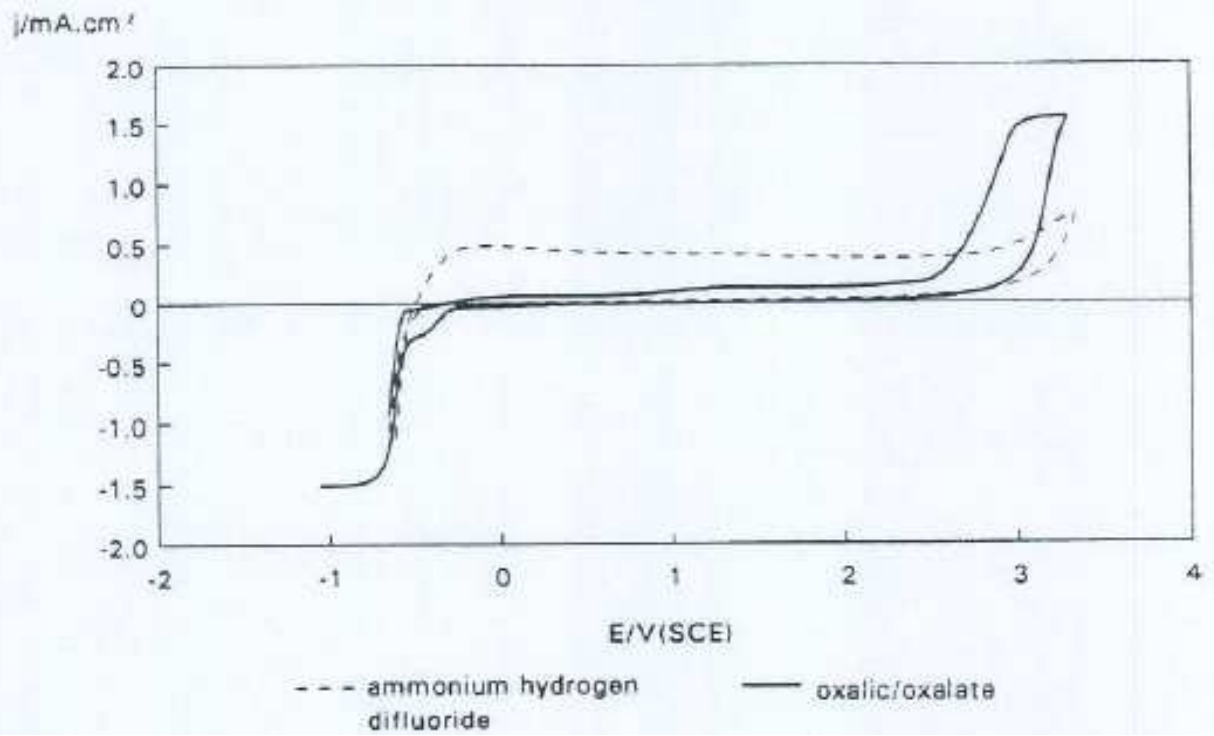

Figure 5: Superposition of voltammetric profiles of titanium electrodes treated by method I and II. $E_{i}=-0.59 \mathrm{~V}$ vs SCE, v $=50 \mathrm{mV} \mathrm{s}^{-1}$, room temperature, electrolyte $1 \mathrm{M}$ $\mathrm{HNO}_{3}$.
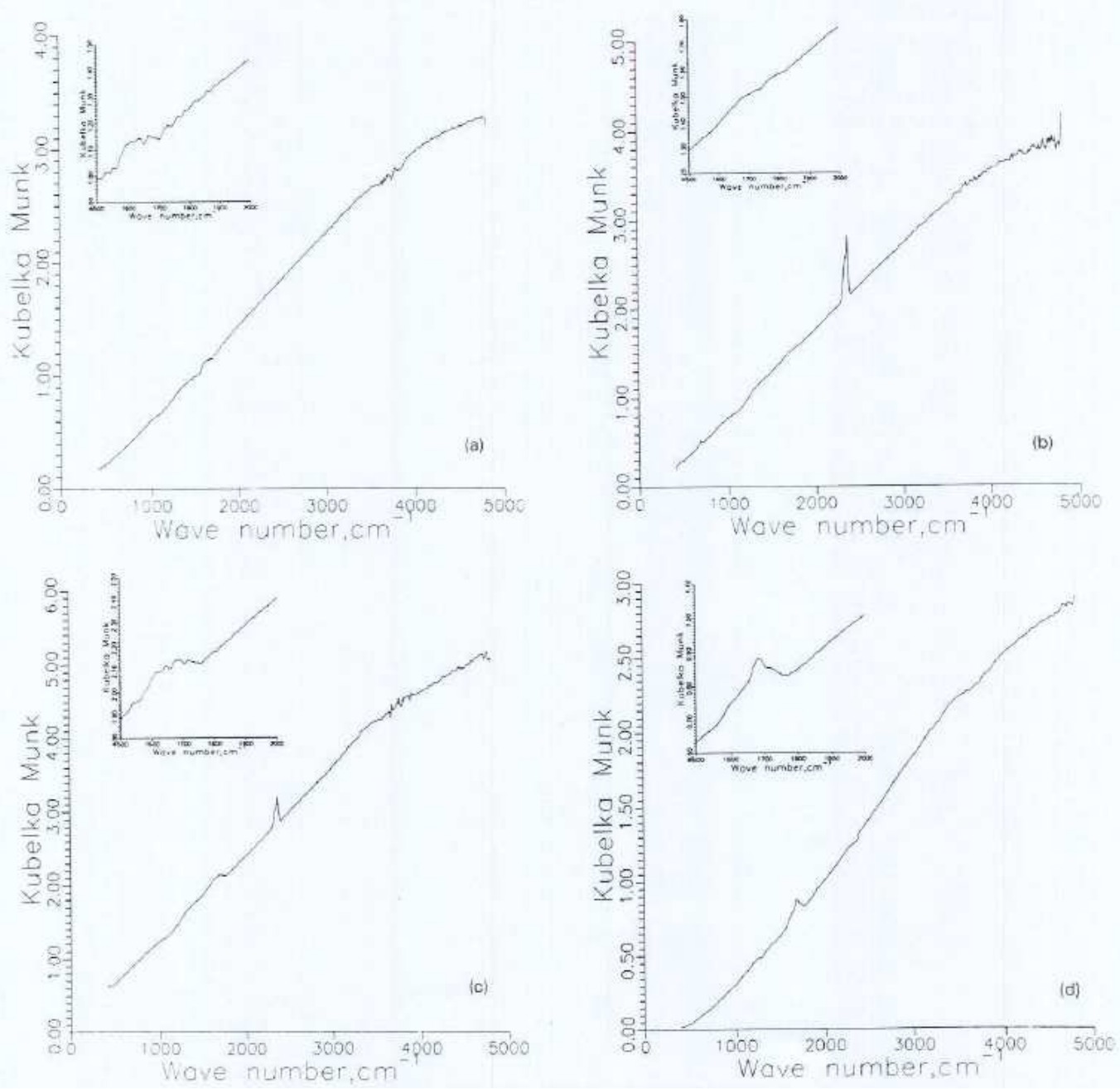
Figure 6: FTIR spectra of titanium surface treated with method (II) for different times of oxalic-oxalate chemical attack: (6a) 0 hours. (6b) 0.5 hours. (6c) 2 hours. (6d) 3 hours.

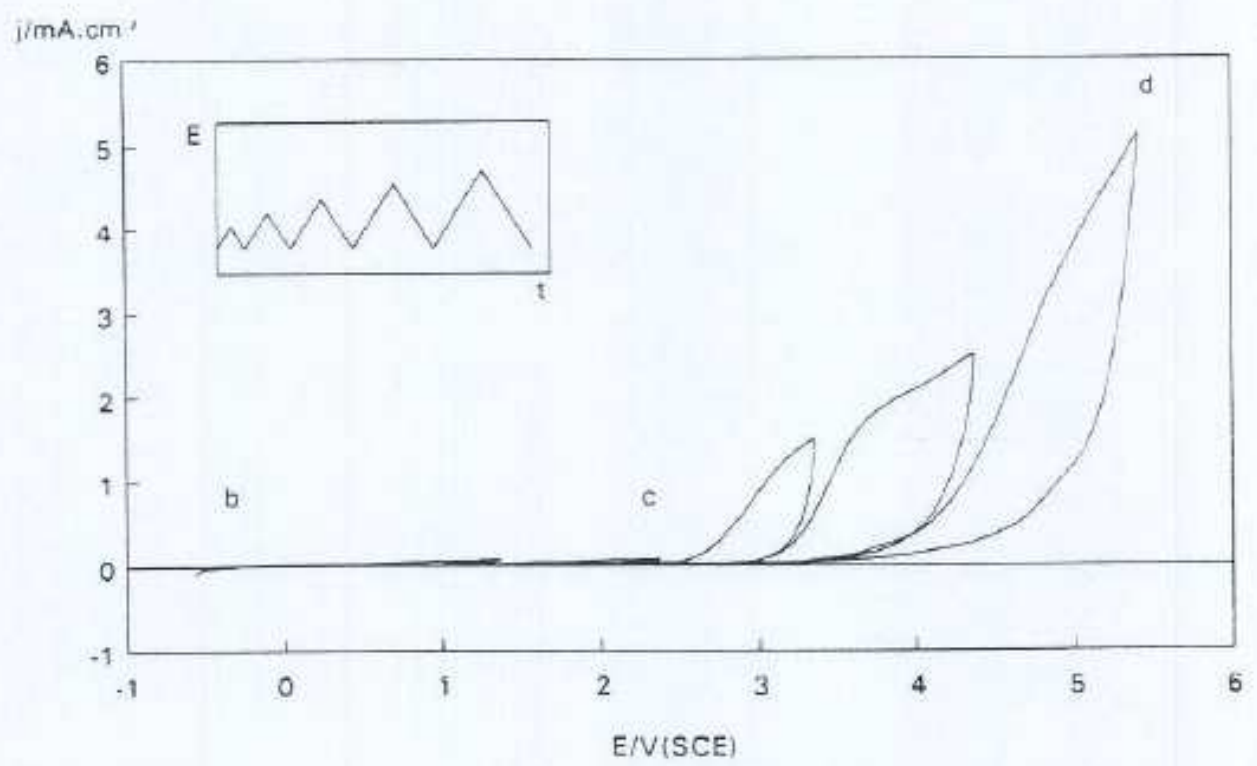

Figure 7: Voltammetric $\mathrm{j}$-E profile for a titanium electrode treated with method (II). $\mathrm{E}_{\mathrm{i}}$ $=-0.59 \mathrm{~V}, \mathrm{v}=50 \mathrm{mV} \mathrm{s}^{-1}$, room temperature, electrolyte $1 \mathrm{M} \mathrm{HNO}_{3}$.

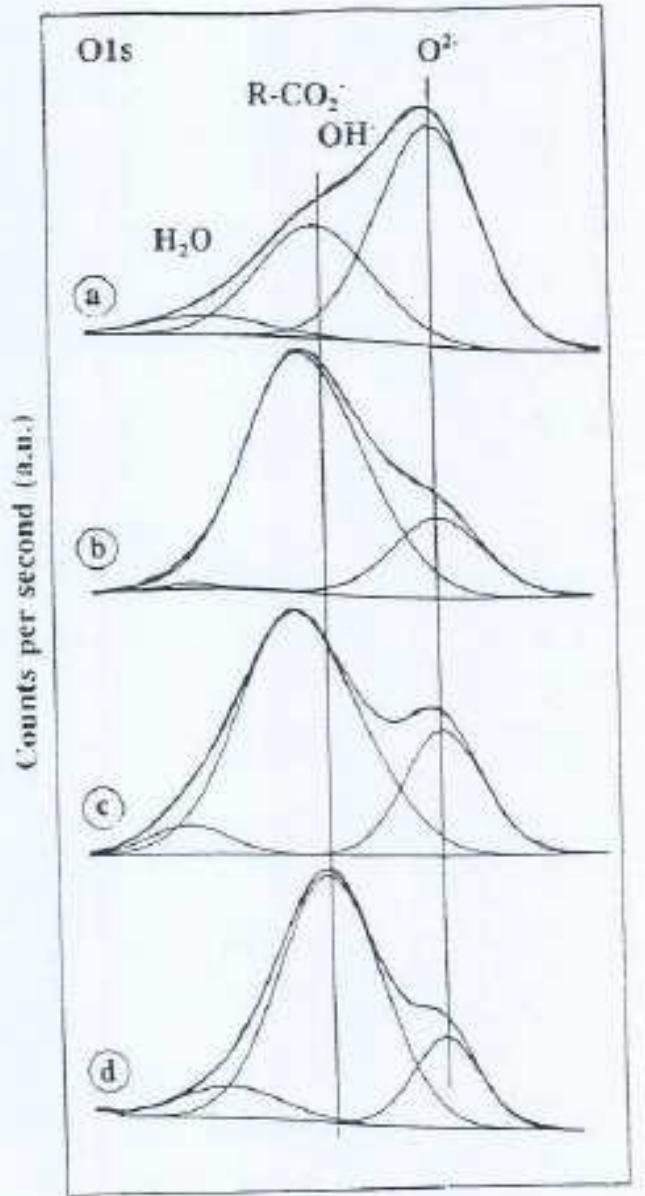

$\mathrm{BE}-(\mathrm{EV})$ 
Figure 8: O1s spectra of a Ti electrode polarized at different potentials. (8a) nonpolarized electrode. (8b) polarized electrode at $-0.59 \mathrm{~V}$. (8c) polarized electrode at 2.34 $\mathrm{V}$ and (8d) polarized electrode at $\mathrm{E}>6 \mathrm{~V}$.

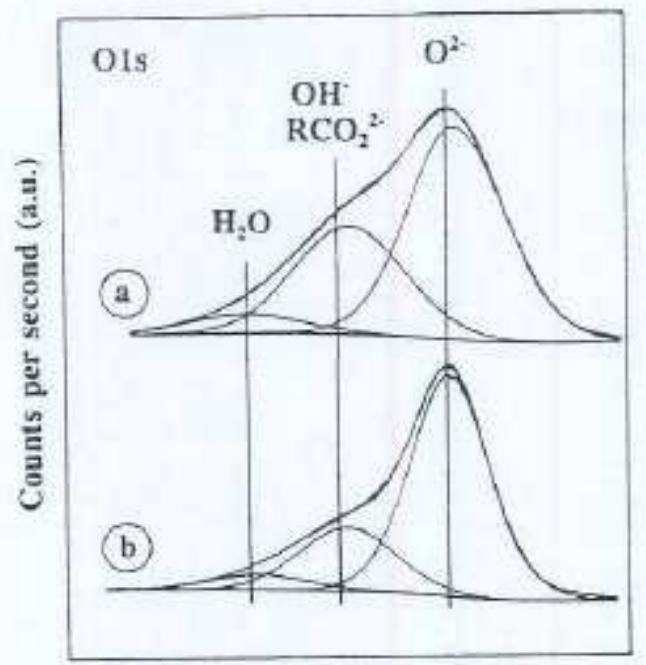

$\mathrm{BE}(\mathrm{eV})$

Figure 9: O1s spectra for titanium surface treated with: (a) method (II). (b) Wabner's Method.

\section{LEGEND OF THE TABLES}

\begin{tabular}{|c|c|c||}
\hline \hline Spectrum & O1s BE $(\mathbf{e V})$ & Species \\
\hline \multirow{2}{*}{$9 \mathrm{a}$} & 529.9 & $\mathrm{O}^{2-}$ \\
& 531.8 & $\left(-\mathrm{CO}_{2}^{2-}-\mathrm{OH}^{-}\right)$ \\
& 533.5 & $\mathrm{H}_{2} \mathrm{O}$ \\
\hline \multirow{2}{*}{$9 \mathrm{~b}$} & 529.9 & $\mathrm{O}^{2-}$ \\
& 532 & $-\mathrm{CO}_{2}^{2-}$ \\
\hline \multirow{2}{*}{$9 \mathrm{c}$} & 530 & $\mathrm{O}^{2-}$ \\
& 532 & $-\mathrm{CO}_{2}^{2-}$ \\
\hline \multirow{2}{*}{$9 \mathrm{~d}$} & 533.9 & $\mathrm{H}_{2} \mathrm{O}$ \\
\hline & 529.9 & $\mathrm{O}^{2-}$ \\
\hline
\end{tabular}

Table 1: Binding energy values of core electrons. 